\title{
Cancer Patient Care and its Medical Management in India: the Impact During Covid-19 and Government Funding Assistance
}

\author{
Shashwat Khare ${ }^{1}$ and P. S. Raychaudhuri*2 \\ ${ }^{1}$ MBA (final year) Pharmaceutical Management, Department of Healthcare \& Pharmaceutical Management, \\ School of Management \& Business Studies, Jamia Hamdard University, New Delhi, India \\ ${ }^{2}$ Assistant Professor, Department of Healthcare \& Pharmaceutical Management, School \\ of Management \&t Business Studies, Jamia Hamdard University, New Delhi, India
}

\section{ABSTRACT}

Cancer is emerging as a major public health concern for the entire globe. According to the World Cancer Report, cancer is the world's second most common cause of death. This poses a rapidly increasing threat worldwide to individuals, health systems and economies.Cancer patients are more susceptible to critical illness and death as compared to the general infected population. Various cohort studies were conducted in China between December 2019 to June 2020;it was inspected that among overall cancer patients admitted in hospital during the pandemic, 79\% were Covid-19 Positive among which 39\% died in ICU; whereas among all general population admitted to the same hospital 37\% were Covid positive out of which $8 \%$ died. It suggests that the cancer patients are at more risk due to Covid-19 pandemic outbreak. In order to prevent 7 million cancer deaths over the next decade, countries must expedite their health care system. In low-income and middle-income countries,during the next decade, the incidence of cancer is expected to almost double.In 2018 India had about 1.16 million cancer cases, 784800 cancer deaths amongits population of 1.35 billion people. Furthermore, the treatment cost for more than $40 \%$ of cancer hospitalization is made by selling the assets and borrowing from relatives; they incur out-of-pocket (OOPE) expenditure in the private sector and can cost more than 20 percent of their annual per capita household spending.And over 76\% of cancer patient families faced financial problems during treatment. The main aim objective of the study was to understand the cancer scenario in India, its treatment cost implications and various treatment facilities and different funding assistance cum Health schemes implemented by central and state governments in India.The data is collected from secondary sources and descriptive study was performed. Therefore in conclusion we find that, we require effective prevention for surviving against cancer along with the proper awareness of the funding schemes by the government for the cancer patients and greater investment in the healthcare infrastructure needs proper attention.

KEY WORDS: CANCER BURDEN, CANCER FACILITIES, COST OF TREATMENT, DIRECT AND INDIRECT COST, GOVERNMENT SCHEMES, CANCER MANAGEMENT IN COVID- 19.

\section{ARTICLE INFORMATION}

Received 27th Oct 2020 Accepted after revision 18th Dec 2020 Print ISSN: 0974-6455 Online ISSN: 2321-4007 CODEN: BBRCBA

Thomson Reuters ISI Web of Science Clarivate Analytics USA and Crossref Indexed Journal

\section{Clarivate
Analytics}

NAAS Journal Score 2020 (4.31)

A Society of Science and Nature Publication,

Bhopal India 2020. All rights reserved.

Online Contents Available at: http//www.bbrc.in/

Doi: http://dx.doi.org/10.21786/bbrc/13.15/28

\section{INTRODUCTION}

The generic non-communicable disease (NCD) which is distinguished by the development of life-threatening (neo-plasms, cancerous) abnormal cells (tumour/lump) in any part of the body is termed as Cancer which is derived from the Greek word "Karkinos" (for crabs) (Rajpal, S et al., 2018). By the end of December 2019 following 
Coronavirus(COVID-19) outbreak in Wuhan in China, the virus speedily expanded across 215 countries around the globe. The World Health Organization announced it as a pandemic on 11th March 2020. The Covid-19 pandemic disrupted various healthcare services including cancer care services which lead to transformations in healthcare services across the globe. (MitraManasij et al., 2020).

Due to Covid-19 outbreak cancer patient faced a lack of resource pressure. For example, limited resource availability led to a delay in cancer diagnosis, untreated/ undetected cases. (Yadav,Sunishtha Singh et al., 2020). According to the International Agency for Research on
Cancer (WHO), the load of cancer is predicted to be twice over the next ten years among middle and low-income countries. WHO declared an advisory stating that kids (below 10 years), old people(above 60 years), patients with breathing problems, diabetic patients, heart patients and cancer patients should follow quarantine stay at their home to save themselves from pandemic(Yadav,Sunishtha Singh et al., 2020).A study was conducted in India to estimate the prevalence of 28 different types of cancer in every state of the country between 1990 to 2016 and it was found that the incidence of new cases of cancer as well as deaths due to cancer have doubled in India between 1990 to 2016. (ICMR, NICPR, 2020).

Table 1. As per the Cancer statistics In India report given by the Indian Council for Medical Research report (ICMR, 2018) and National Institute of Cancer Prevention and Research report (NICPR, 2020).

Avg. No. of people living with the disease

Approximately 2.25 Million

\begin{tabular}{l|l} 
New Cancer Patients Registered every year & Approximately 11,57,294 Lakhs
\end{tabular}

\begin{tabular}{l|c} 
Deaths related to cancer & $7,84,821$ \\
\hline Risk of Developing Cancer before 75years of age & $9.81 \%$ in Males And 9.42\% in Females
\end{tabular}

Risk of Death from Cancer before 75 years of age $\quad$ 7.34\% in Males And 6.28\% in Females

(Source: ICMR, 2018;NICPR, 2020)

- Total Deaths due to Cancer in $2018=7,84,821$

- $\quad$ Men $=4,13,519$

- $\quad$ Females $=3,71,302$

The cancer disease has led to catastrophic health spending anddistress financing, which leads to increased expenditure before death in India. In India, the out-ofpocket-expenditure (OOPE) has become approximately three times higher for private inpatient cancer-care. A huge amount (approximately 40\%) of the treatment cost for cancer patients are covered by the sales of the assets, borrowing, or contributions from friends and family. The Facilities provided by the government for cancer care are woefully inadequate, and due to this, there is a large presence for cancer facilities in the private sector (Robert D. Smith et al., 2019).

They incur out-of-pocket expenditure (OOPE) in the private sector and can cost more than 20 percent of their annual per capita household spending.And over $76 \%$ of cancer patient families faced financial problems during treatment. It is estimated that the average total expenditure is Rs. 29, 066 (at 2014 purchasing power parity)for public sector hospitals and Rs. 84, 320 for private sector hospitals (Rajpal, Sunil et al., 2014).

Objectives: The main aim objective of the study was to understand the cancer scenario in India, its treatment facilities, the patient care management during and post Covid pandemic for the cancer patients, its implications for cost of treatment and create awareness about various government funding schemes;

A) To explore and understand the cancer disease scenario in India and its cost of treatment implications in Government and Private Hospitals.

B) To understand the management of cancer patients' treatment during and post Covid pandemic.

C) To review and create awareness about the various Health Schemes implemented by both the central and state governments for funding assistance and helping the cancer patients.

Literature Review: Cancer has become the biggest reason for concern for human beings globally. The main reason for such a high rate of incidence is due to internal, external, or environmental factors. (Ali, Imran et al., 2011). The regular change in lifestyle, improved lifespan, and good control of infectious diseases, the incidence of the non-communicable disease has increased in developing countries (Singh, M et al., 2018).Lack of insurance policies, reduced government expenditure, and huge out-of-pocket expenditure create a deliberately vicious cycle for the patients. Only $29.6 \%$ of patients were having insurance coverage. The patients facing catastrophic impact was the most in semi-private wards at $86.7 \%$ and further followed by those in public and private hospitals. (Basavaiah, G et al., 2018).

\section{MATERIAL AND METHODS}

The data was collected from secondary sources. The data was collected from various Published Research articles, Google Scholar, Pubmed.The other sources of data were collected from news press releases from Economic Times and Times of India, Government of India, WHO cancer report 2020. A descriptive study was performed. 


\section{RESULTS AND DISCUSSION}

A) Cancer Scenario in India: The report given by WHO says that every 1 out of 10 Indians has the risk to develop cancer during his/her lifetime and 1 Indian out of 15 Indians will die due to Cancer (WHO IARC, 2020;
Financial Express, 4th February 2020). As estimated by the World Cancer report the cancer burden in India (WHO IARC,2020; Financial Express, 4th February 2020)

- New Cases Registered - 1.16 million

- Deaths due to Cancer - 7,84,800

Table 2. Total No of New Cancer Cases Registered in 2018 (As per the World Cancer Report 2020 released by WHO, IARC (Financial Express, 4th February 2020).

New Registered Cases in Men $=570,000$

New Registered Cases in Women $=587,000$

Stomach Cancer $=(39,000$ cases $)$

Ovarian Cancer $=(36,000$ cases $)$

Colorectal Cancer $=(37,000$ cases $)$

Colorectal Cancer $=(20,000$ cases $)$

Oral Cancer $=(92,000$ cases $) \quad$ Cervical Cancer $=(97,000$ cases $)$

Lung Cancer $=(49,000$ cases $) \quad$ Breast Cancer $=(162,500$ cases $)$

Oesophageal Cancer $=(34,000$ cases $) \quad$ Oral Cancer $=(28,000$ cases $)$

\begin{tabular}{l|l}
\hline Accounts for $45 \%$ of cases & Accounts for $60 \%$ of cases
\end{tabular}

(Source: World Cancer report 2020, WHO-IARC-Financial Express, 4th February, 2020)

B) Management of Cancer patients in India during and post Covid-19 pandemic

1) Service Delivery: The cancer patients are immunesuppressed due to the reduced immunity as a result of side effects of anti-cancer therapy performed on them; so they have a greater risk of complication and death due to Covid-19 virus. The most cancer patient does not have a choice except to face the outside world and take life-saving treatment. The responsibility for protecting them from the virus lies with government policymakers as well as healthcare providers and workers.

Various techniques such as infection control, covid-19 facilities, cancer segregation, and treatment modification can reduce the exposure of cancer patients to the virus. (Sengupta, Mitu et al., 2020)

a) Infection Control: Infection Control's primary aim is to decrease viral transmission between medical personnel, patients and caregivers.This can be done by various means, such as training courses for hospital staff about the proper use of PPE (Personal Protective equipment) kits, managing patient flow, reducing contact between patients, developing isolation wards for the confirmed cases of Covid-19, transferring patient to the areas with a low incidence of infections. (Pramesh, CS et al., 2020)The routine consultation and follow-up could be done through telemedicine. Theaerosol containment and disinfectant cum sanitisation measures including instruments sanitisation scrubbing should be established during emergency, endoscopies and surgery in clinics and hospitals. The other measures of sanitisation and hygiene and pre-test of caregivers/ health workers must be done before collection of the blood sample from home and home delivery for medicines, regular screening of staff and patient before entry into clinics or hospitals, reducing the entry of attendants and relatives in hospitals and clinics.(Sengupta, Mitu et al., 2020) b) Segregation of cancer and covid-19 facilities: Separating the facilities used to treat Covid-19 patients is the most important step to ensure safety for cancer patients during treatment in a pandemic.; separate blocks orbuilding should be used which has been strongly recommended by the UK's National Health Service, and other professional medical associations and international bodies.(Pramesh CS, et al., 2020) Due to limited health infrastructure of the country multi-speciality hospitals are under high pressure as they are an important part of advanced cancer care in India. Merging of the cancer facilities with the Covid-19 facilities is not a defensible option as the cancer patients are at higher risk as compared to the general population.(Sengupta, Mitu et al., 2020;Damani, Anuja et al., 2020)

c) Treatment Modifications: The modification of aspects of treatment is another way to reduce patient exposure to the virus. In addition to international guidelines that can be used to monitor decisions on customized treatment adjustment, there are several general variables that include the tumor's biological characteristics, the patient's clinical condition, and the treatment's possible benefit from the predicted adverse effects.( Curigliano, $\mathrm{G}$ et al., 2020) Patients may be divided into various priority categories for successful cancer therapy; higher priority may be given to patients whose condition is clinically unstable or life-threatening or who are at risk of developing significant comorbidities and lower priority may be given to patients in the early stage of cancer who do not need immediate treatment or who are in the second or third line of care.( Ramesh, Anita et al., 2020).

Treatment modification can be avoided for high priority patients but it can be considered for a group of lower priority by different means such as switching to oral therapies from intravenous means or altering the 
frequency of maintenance treatment.(Sengupta, Mitu et al., 2020).

\section{2) Access to health care-}

a) Physical access: Due to the poor geographical spread of medical facilities present in India, the cancer patient has to travel long distances to receive treatment and care. Complex restrictions on intra-and-inter-state travel and disruption of public transport facilities have been imposed during the lockdown process in India.This led to grave difficulties for many cancer patients. The cancer patients should be provided with targeted and effective support such as easy procedures for obtaining travel passes etc.(Curigliano, G et al., 2020;Sengupta, Mitu et al., 2020).

b) Financial access: In India, the cost for treatment for the cancer patient is highest among all non-communicable diseases. The out-of-pocket expenditure is 2.5 times for cancer hospitalization than that of overall average hospitalization expenditure, which leads to selling off assets, borrowing money etc.(Sengupta, Mitu et al., 2020). COVID-19 pandemic had further worsened the bad situation. Due to the loss of job or loss of income source during this pandemic worldwide, it had made the situation more worse as the cancer patient and their family members have fewer resources to pay the treatment cost. Most numbers of the cancer patient are under financial stress and should be targeted for various types of financial support from government and private sources in the form of insurance schemes, special loans, grants etc. (Damani, Anuja et al., 2020).

c) Main Health Access: Most cancers are diagnosed in late stages when medical results are low and many cancer cases are related to preventable causes such as tobacco use and infections.First the primary healthcare providers are confronted with the complaint of symptoms that may be suggestive of cancer; then it is also the duty of the healthcare provider to encourage cancer awareness. The huge diversion of human capital to handle the pandemic and materials has hit India's healthcare system.(Harky, Amer et al., 2020)Accredited social health activist (ASHA) has been diverted to health issues linked to service Covid19 cases. It is the first health option that vulnerable and disadvantaged groups of the population have access to; their routine work is the promotion of maternal health, family planning and child immunization. Some ASHA workers have been trained in cancer prevention particularly in early detection and treatment ofbreast and cervical cancer,as early detection can prevent high death rates due to this cancer. Thus the most important step towards safeguarding early detection is at the primary level. (Pandey, A et al., 2020;Sengupta, Mitu et al., 2020).

3) Communication: Patients have been prevented from pursuing high priority medical care and treatment by misleading knowledge about the pandemic. Many cancer patients have been led to believe that when taking medical care, there are no effective ways to avoid infection with the virus. However if adequate protective measures are taken against infection, cancer treatment may be administered safely. (Pramesh, CS et al., 2020) The main challenge for government policymakers and healthcare providers is to ensure that correct and trustworthy information is conveyed to cancer patients regarding the managing of illness, evidence-based knowledge about the virus, its mode of transmission, origins, symptoms etc.All pandemic information should be gathered from official sources, such as the portal of the Indian Ministry of Health and Family Welfare Coronavirus and the Covid19 response portal of the World Health Organization. (Sengupta, Mitu et al., 2020).

C) Cancer Treatment Centres and Financial Aids for Cancer Burden In India: Tertiary Regional Cancer Treatment Centres- Under the National Cancer Control Programme, initiated by the Government of India, there are 27 cancer centres in India.(ICMR-NICPR, 2020)

Financial Aids Provided By the Government-(ICMRNICPR, 2020).

\section{1) Government of India Funded Schemes-(ICMR- NICPR, 2020).}

\begin{abstract}
A) Announcement of Ayushman Bharat By Government of India- The two crucial initiatives in the Health Sector (ICMR- NICPR, 2020).
\end{abstract}

I. Health and Wellness Centres - National Health Policy, 2017 has successfully visualized Health And Wellness Centres, which played a very crucial role in making the foundation of India's Health System. (ICMR- NICPR, 2020).

II. National Health Protection Scheme- It is the second flagship program that runs under Ayushman Bharat. Under this scheme, 10 crore poor and vulnerable families are covered and providing coverage up to the sum of 5 lakh rupees per family for their secondary and tertiary care hospitalization. (ICMR- NICPR, 2020).

B) Prime Minister's National Relief Funds- These funds came into existence by Late. Prime Minister of India Pt. Jawaharlal Nehru in the year 1948. The funds (PMNRF) are mainly utilized to provide relief to the families of those people who were killed in any natural calamities such as floods, cyclones, and earthquakes, etc. (ICMRNICPR, 2020).

C) Ministry of Health and Family Welfare- This government body gives financial support to the poor patients for their treatment at different hospitals present in the country under two schemes(ICMR- NICPR, 2020).

I. RashtriyaArogyaNidhi (RAN)- Provides Financial Assistance to poor patients for treatment at various hospitals present in the country. The amount up to Rs. 1,00,000 per every respectable case reported for treatment in any respective hospital/centres. (ICMRNICPR, 2020). 
II. State IIIness Assistance Funds (SIAF)- The state's Illness Assistance Funds are set up by all state govt./ Union Territory Administration where the funds for each of these states are released by the central government. These funds also receive contributions from donors (RAS). (ICMR- NICPR, 2020).

D) Central Government Health Scheme (CGHS)- This scheme is only applicable for retired Central Government Employees and dependents to provide the best cancer treatment facilities. (ICMR- NICPR, 2020).

E) Railway Concession For Cancer Patients and one Bystander- The Cancer patient travel is free and only $25 \%$ of actual class II fare has to be paid by the bystander. (ICMR- NICPR, 2020).

F) Air Concession For Cancer Patients- The Cancer Patient has to only pay 50\% of the basic fare of the normal economy class. (ICMR- NICPR, 2020).

G) RashtriyaSwasthyaBimaYojna (RSBY)- Only the families under Below Poverty line, Mahatma Gandhi Rural Employment Guarantee Act(MGNREGA) job cardholder. (ICMR- NICPR, 2020).

H) Income Tax Relief for cancer Patient- Form No. 10 I have to be filled for getting these funds.

Funds by state Government- (ICMR- NICPR, 2020) Chief Minister of Relief Funds- (ICMR- NICPR, 2020)

These funds are also provided for the treatment of distressed people who are affected by various natural calamities. These funds also assist the poor and needy patients for the treatment of cancer, cardiac surgery, Liver and multi-organ failure, etc. All states present in the country have set up an Illness Assistance Program except Assam, Meghalaya, and Nagaland.

\section{CONCLUSION}

This article gives a fair idea about the cancer burden over the world as well with special reference to India. The top 6 cancer illnesses present in India are Lung cancer, Breast Cancer, Oral Cavity Cancer, Cervical Cancer, Stomach Cancer, and Colorectal Cancer. This cancer accounts for $40 \%$ of total deaths among males and $60 \%$ of total death among females. The maximum death taking place in the country is due to Breast Cancer, Oral Cavity Cancer, and Cervical Cancer. According to the GLOBOCAN 2018 data, there were 87,090 deaths due to Breast Cancer, 72,161 deaths due to Oral Cancer, 60,078 Deaths due to cervical cancer in India, which is the reason for great concern for the Government of India.

There are various Tertiary cancer care centres present in the country, mainly the government hospitals that areidentified by the Government of India in every state except Assam, Nagaland, Meghalaya. With the help of these canters, the government is trying to help the patient with their treatment by providing various sources of funding. Due to the increased load of cancer patients, all the government hospitals are full and the patient has to go to a private hospital to get better care for cancer which ultimately leads to the situation of the bankruptcy of the poor and low-income families. The Government of India'sAyushman Bharat scheme is a good step taken by the government to provide better treatment facilities to the patients at a low cost.

\section{REFERENCES}

Ali Imran, Waseem A. Wani, KishwarSaleem (2011): Cancer Scenario in India with Future Perspectiveshttps:// www.researchgate.net/publication/230560896_Cancer_ Scenario_in_India_with_Future_Perspectives 20th May 2020.

Basavaiah Guruchanna, Rent D. Priyanka, Rent G. Eugene, Sullivan Richard, et al., (2018): Financial Impact of Complex Cancer Surgery in India: A study of Pancreatic Cancer. https://ascopubs.org/doi/ pdf/10.1200/JG0.17.00151 22nd May 2020.

Cancer Statistics (2020)Indian Council for Medical Research(ICMR), National Institute of Cancer Prevention and Research(NICPR).http://cancerindia.org.in/cancerstatistics/ 5th June 2020.

Curigliano G., Banerjee S., Cervantes A., Garassino M.C., Girard N., et al., (2020): Managing cancer Patients during the Covid-19 pandemic: an ESMO multidisciplinary expert consensus https://www.annalsofoncology.org/ article/S0923-7534(20)39948-8/fulltext7th November 2020.

Damani Anuja, Ghoshal Arunangshu, Salins Naveen et al., (2020): Approaches and Best Practices for Managing Cancer Pain within the Constraints of the COVID-19 Pandemic in India https://www.researchgate. net/publication/342593235_Approaches_and_Best_ Practices_for_Managing_Cancer_Pain_within_the Constraints_of_the_COVID-19_Pandemic_in_India28th November 2020.

Dey Sushmi (03 November 2019), The Times Of India Press Release - Cancer cases rise by over 300\% in 1 year. https://timesofindia.indiatimes.com/india/cancer-casesrise-by-over-300-in-1-year/articleshow/71872746. cms\#: :text=NEW\%20DELHI\%3A\%20Cases\%20of\%20 common,National\%20Health\%20Profile\%2 $\% 20$ 2019\%20data. 15th June 2020.

Financial Express (4th February 2020)(Time - 4:30 PM): World Cancer Day: Alarming! One in 10 Indians will develop cancer in their lifetime, says WHO. https://www.financialexpress.com/lifestyle/ health/world-cancer-day-2020-alarming-one-in-10indians-will-develop-cancer-in-their-lifetime-sayswho/1855818/10thOctober 2020

HarkyAmer, Chiu Chun Ming, Yau Thomas Ho Lai, Lai SheungHeng Daniel (2020): Cancer Patient Care during COVID-19 https://www.cell.com/cancer-cell/fulltext/ S1535-6108(20)30256-7\#\%20 08thDecember 2020. 
Indian Council for Medical Research(ICMR)(2018), National Institute of Cancer Prevention and Research(NICPR)- Incidence Rate of Cancer in 2016 in Different States And Union Territories Of India. http://cancerindia.org.in/geographic-distributionburden-cancers-india/incidence-rate-of-cancer-in2016-in-different-states-and-union-territories-ofindia/22ndOctober 2020.

Mitra Manasij, BasuMaitraye (2020): A Study on Challenges to Health Care Delivery Faced by Cancer Patients in India During the COVID-19 Pandemichttps:// journals.sagepub.com/doi/full/10.1177/2150132720942 7053rdDecember 2020.

Mohanti BK, Mukhopadhyay A, Das S, Sharma K, Dash S(2011): Estimating the economic burden of cancer at a tertiary public hospital: a study at the All India Institute of Medical Sciences, Discussion Paper 11-09. https://www.researchgate.net/publication/254424277_ Estimating_the_economic_burden_of_cancer_at_a_ tertiary_public_hospital_A_Study_at_the_All_India_ Institute_of_Medical_Sciences29th July 2020.

Nair KS, Raj S, Tiwari VK, Piang LK (2013): Treatment for Cancer: Experiences of Patients in Public Hospitals in India. https://www.researchgate.net/ publication/258212809_Cost_of_Treatment_for_ Cancer_Experiences_of_Patients_in_Public_Hospitals_ in_India3rd August 2020.

Pandey A, Mala R, Neelam C, Mridula P, et al., (2020): Impact of COVID-19 pandemic on cancer care delivery: A Real-World Experience https://www.medrxiv. org/content/10.1101/2020.09.01.20183145v1.full. pdf10thDecember 2020.

Pramesh CS, Gupta Sudeep, LaskarSarbaniGhosh, SengarManju et al., (2020): The COVID-19 pandemic and the Tata Memorial Centre response https://www. indianjcancer.com/article.asp?issn=0019-509X;year=2 020 ; volume $=57 ;$ issue $=2 ;$ spage $=123$; epage $=128$; aulast $=$ The10thDecember 2020.

Rajpal Sunil, Kumar Abhishek, Joe William (2018). Economic Burden of cancer in India: Evidence from cross-nationally representative household survey 2014. https://doi.org/10.1371/journal.pone.0193320 10th September 2020.
Ramesh Anita,SsoundarajanRaji (2020): Abstract P0-008: Cancer care during the COVID-19 pandemic in Southern India https://clincancerres.aacrjournals. org/content/26/18_Supplement/P0-0085thDecember 2020.

Robert D. Smith, Mohandas K. Mallath (2019): History of the growing Burden of Cancer in India: From Antiquity to the 21st century. https://ascopubs.org/doi/ pdf/10.1200/JG0.19.00048 October/2020.14thOctober 2020.

Sengupta Mitu, AroraAsit (2020): Protecting Cancer Care through theCovid-19 Crisis and it's Aftermathhttps:// www.orfonline.org/research/protecting-cancer-carethrough-the-covid-19-crisis-and-its-aftermath/\# edn1330th November 2020.

Singh Mayank, Prasad Prakash Chandra, Singh DebrajThoudam, Kumar Lalit (2018): Cancer Research in India: Challenges and Opportunities https://www.ncbi. nlm.nih.gov/pmc/articles/PMC6362726/21st September 2020.

Sirohi Bhawna (2010): Cancer Management in the twenty-first century in India https://www.ncbi.nlm.nih. gov/pmc/articles/PMC2970933/ 23rd August 2020.

Sunu Cyriac, Christoper M.Booth (2019) Delivery of Cancer Care In India and Canada: Opportunities for Bidirectional Learning https://ascopubs.org/doi/ abs/10.1200/JG0.19.0030215th0ctober 2020

The New Indian Express (2nd November 2019 )(Time - 9:31 AM): Common Cancer prevalence may be way higher than estimated. https://www.newindianexpress. com/nation/2019/nov/02/common-cancer-prevalencemay-be-way-higher-than-estimated-2055972. html20thOctober 2020.

World Cancer Report 2020, International Agency For Research On Cancer(IARC) https://www.iarc.fr/ featured-news/new-world-cancer-report/\#prelease 30th September 2020.

Yadav Sunishtha Singh, Zain Maryam, SahaiPragati, PorwalShalini, ChauhanVandana (2020): Challenges Encountered in Cancer Care and ManagementDuring Covid-19 in South Asian Countries https:// www.researchgate.net/publication/345762869_ COVID_19_and_cancer_management_in_Asian_ countries1stDecember 2020. 